\title{
In-situ trace-elements of silicates in mafic intrusions
}

\author{
S.H. Yang ${ }^{1 *}$, W.D. Maier ${ }^{2}$, T. Karinen ${ }^{3}$, M. Moilainen ${ }^{1}$, G. Delmotte ${ }^{1}$, B. Datar ${ }^{1}$, \\ K. Luolavirta ${ }^{1}$, K. Kärenlampi ${ }^{1}$, M. Jez ${ }^{1}$, and H. O’Brien ${ }^{2}$ \\ ${ }^{1}$ Oulu Mining School, University of Oulu \\ ${ }^{2}$ Cardiff University \\ ${ }^{3}$ Geological Survey of Finland, Rovaniemi \\ ${ }^{4}$ Geological Survey of Finland, Espoo \\ *Corresponding author e-mail: shenghong.yang@oulu.fi
}

\section{Introduction and background to current research}

In situ trace elements composition of silicate minerals can be potentially used to constrain the parental magma composition. However, except crystallization of minerals from magma, other processes may also modify the composition of silicate, such as equilibration of trapped liquid and cumulus minerals, sub-solidus equilibration between different minerals. In this abstract, we compare different types of intrusions, and try to understand controlling factors on the composition of silicates, which is important for the further application of this method in the study of mafic intrusions.

\section{Research questions at hand}

In Bushveld complex, the Main zone is relatively less dynamic than other stratigraphy. We have systematically studied plagioclase, clinopyroxene and orthopyroxene composition of this interval (Yang et al., 2019). One interesting feature is that the compatible elements of pyroxenes (e.g., $\mathrm{Ni}, \mathrm{Cr}$ ) generally follow $\mathrm{Mg} \#$ variation trend, indicating a crystal fractionation process. The progressive enrichment of Ti from core to rim is preserved in plagioclase, but not for other incompatible trace elements (e.g., REE), indicating that in large layered intrusions (e.g., Bushveld), trapped liquid shift may have played an important role (Yang et al., 2019).

On the other hand, changing of composition of incompatible trace elements from core to rim is well preserved in Finnish intrusions, indicating a faster cooling magmatic system due to smaller size, and thus can be well applied to constrain the primary magmatic processes. In Kevitsa, there are three major types of ores. Normally ore, Ni-PGE ore and false ores. The NiPGE ore is characterized by its unusual high Ni content and also high incompatible trace element contents. The smooth trace element signal during laser ablation analyses confirmed that there is no inclusions in the silicate minerals, and this unusual feature thus reflect the original magmatic feature (Figure 1). In Kevitsa, it is confirmed that the parental magma of NiPGE ore should have both high $\mathrm{Ni}$ and incompatible elements contents. The sulfide saturated intrusion (normal and false ore in Kevitsa) show clear Ni depletion in clinopyroxene compared to sulfide under saturated magma (e.g., Main zone in Bushveld), and this can be utilized as a sign for sulfide saturation and related exploration (Figure 2). 

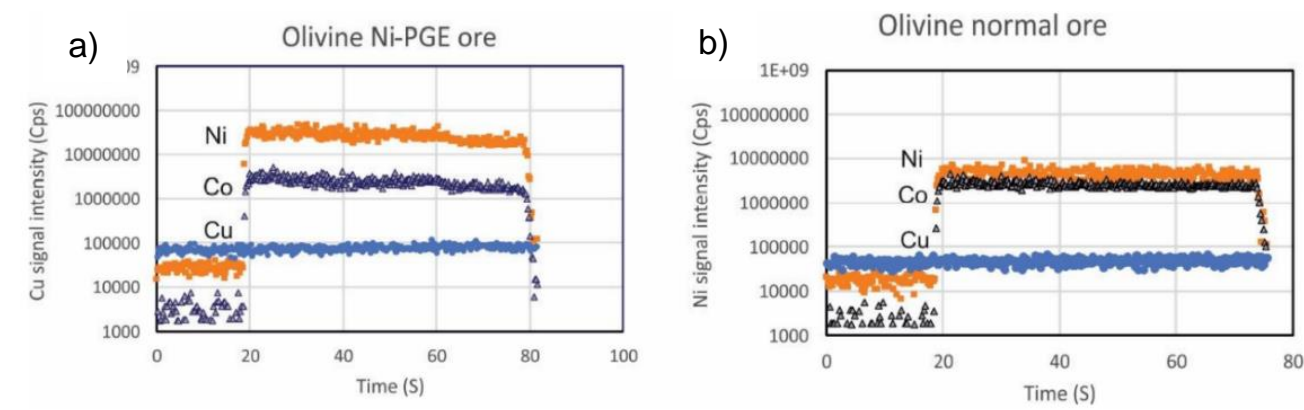

Figure 3. TRA spectra (counts per second vs. time in seconds) from laser ablation analyses of a olivine from Ni-PGE ore (a) and normal ore (b).

In Mustavaara, $\mathrm{V}$ in plagioclase show compatible behavior and clearly different than other incompatible elements, which may indicates co-precipitation of oxide and silicate from magma. Plagioclase in the ore zone and upper zone show depletion of Ti, can thus be used as a sign for saturation of oxides in mafic intrusions.

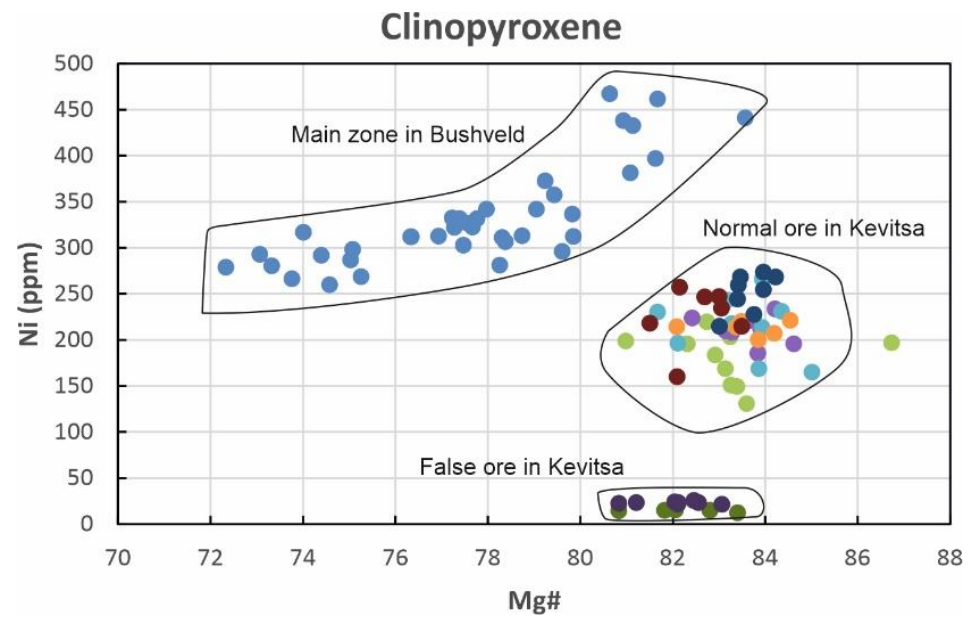

Figure 2. $\mathrm{Ni}$ and $\mathrm{Mg \#}$ of clinopyroxene from false ore and normal ore in Kevitsa which experienced different degrees of sulfide saturation, compared with sulfide undersaturated magma in the Main zone of Bushveld.

\section{Acknowledgements}

This project is funded by Renlund foundation.

\section{References:}

Yang, S.H., Maier, W.D., Godel, B., Barnes, S.J., Hanski, E. and O’Brien, H., 2019. Parental magma composition of the Main Zone of the Bushveld Complex: evidence from in situ LA-ICP-MS trace element analysis of silicate minerals in the cumulate rocks. Journal of Petrology, 60(2), pp.359-392. 